www.conferenceie.ase.ro

\title{
E-DEMOCRACY AND E-VOTING USING EMERGING TECHNOLOGIES
}

\author{
Marian STOICA \\ Department of Economic Informatics and Cybernetics \\ Bucharest University of Economic Studies, Romania \\ marians@ase.ro \\ Bogdan GHILIC-MICU \\ Department of Economic Informatics and Cybernetics \\ Bucharest University of Economic Studies, Romania \\ ghilic@ase.ro \\ Marinela MIRCEA \\ Department of Economic Informatics and Cybernetics \\ Bucharest University of Economic Studies, Romania \\ mmircea@ase.ro \\ Panagiotis SINIOROS \\ Technological Educational Institute of Piraeus Athens Greece \\ pasin@teipir.gr
}

\begin{abstract}
Due to increasing influence of online environment over the population, many governments have chosen to switch to using social media, web 2.0 and cloud technologies, thus facilitating the interaction with citizens, relations with institutions and enterprises and cooperation with other governments. In this context, societies get more and more involved in the online environment and support the interaction between individuals while the electronic government concept sees a significant evolution manifested in e-democracy, electronic voting, electronic legislation and electronic services using emerging technologies. Additionally, in the general context of emergency status and crisis due to COVID-19 pandemic, the e-government dimensions become significant, some of its components becoming indispensable in providing a visible response to current pandemic ecosystem: tele-education, telework, tele-services, telemedicine etc. The electronic government term means using electronic communication technologies to improve democratic processes in a country. E-democracy, also known as electronic democracy, means using information and communication technology by the democratic actors in political and government processes, on local, national and international stage. By "political actors" we understand governments, elected officials, mass-media, political organizations and, most important of all, citizens. Electronic vote is the vote cast by means of electronic devices in order to help them manifest their choice or help the vote counting process. Depending on implementation, stand-alone voting machines or internet-connected computers may be used, involving various electronic services, from transmission of results to online voting.
\end{abstract}

Keywords: E-democracy, e-government, e-voting, cloud computing, web 2.0.

JEL classification: $\mathrm{O} 3, \mathrm{P} 14$.

DOI: $10.24818 / \mathrm{ie} 2020.02 .06$

\section{Introduction to E-Government}

The term „electronic government” involves using electronic communication technologies to improve democratic processes in a country. This involves four main components: interaction 
between government and citizen (G2C), which aims to modernize public services provided to citizens; interaction between government and business environment $(\mathrm{G} 2 \mathrm{~B})$; interaction between government and public servants $(\mathrm{G} 2 \mathrm{E})$, which involves using electronic means for communications with government employees or applications that facilitate fulfilment of tasks; interaction between government institutions $(\mathrm{G} 2 \mathrm{G})$ - figure 1. Initially, electronic government appeared from the desire to provide citizens with public services through the means of information and communications technologies (ICT), giving them better opportunities for direct access to government. This supports more active participation of citizens to making public policy decisions, allowing them a greater influence. A better electronic government brings many benefits: government gains increased trust from citizens, there is a more attractive government, evolution towards a more evolved digital society, which may lead to a significant economic progress.

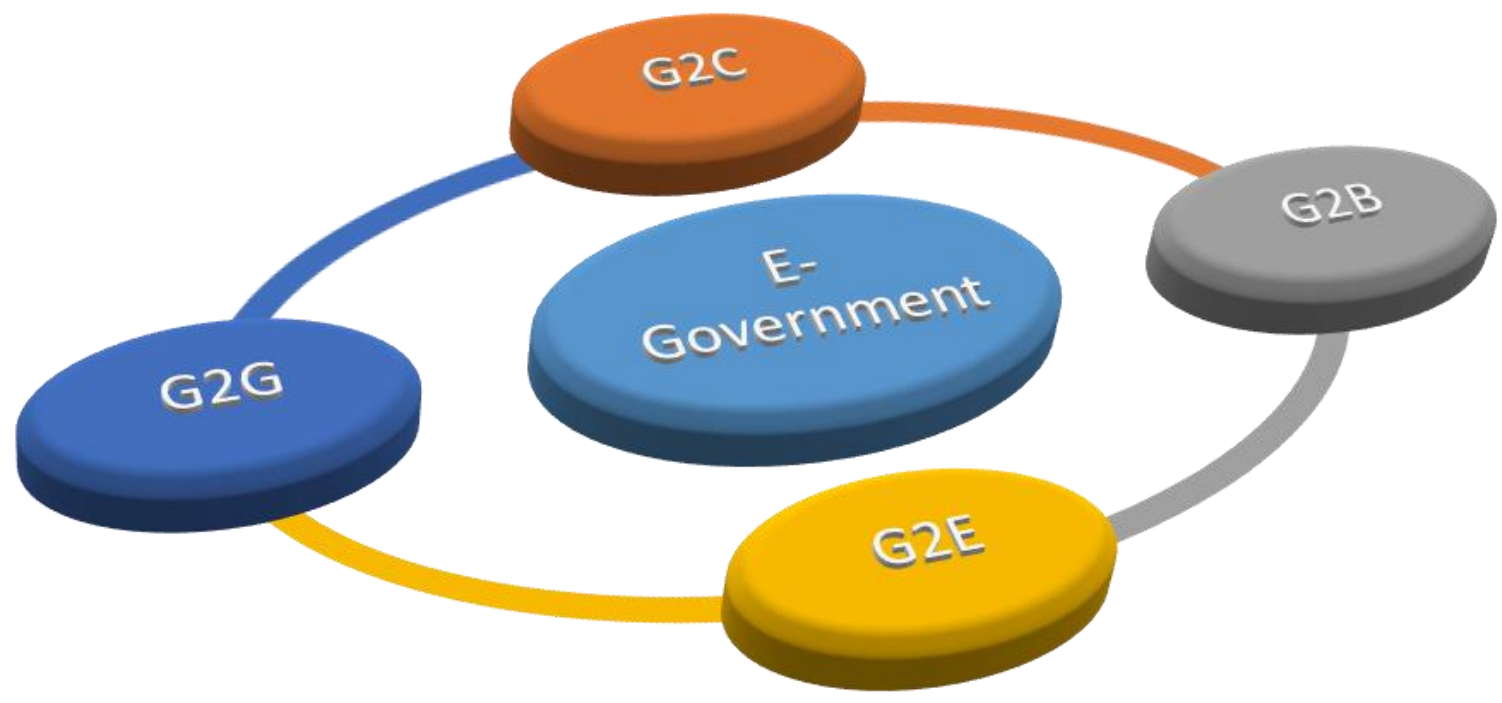

Figure 1. Classical pylons of electronic government

The need to implement new government technologies is more and more obvious these days. There is a desire to call on various instruments like socializing sites to involve more individuals in the political life, to mobilize voters, increase citizen participation to political life, improve public services and favor innovation and economic growth. Thus, governments are forced to implement new emerging technologies, most favored being currently social media and cloud computing.

Web 2.0 technologies designate those web-sites that allow users to interact and share information online, faster and easier, through social media, blogging and web-based community, such sites being more and more dynamical and interconnected. The main features of web 2.0 technologies are: providing simple applications that solve specific problems and that may be accessed from anywhere, anytime, data can be easily shared and collaboration between individuals is encouraged, offering new ways for interaction and collaboration between individuals as well as sharing information with large groups of people.

As for the government, web 2.0 technologies have a significant impact, a long list of applications being already in use. The nature of this impact is characterized mainly by the more active role of users, the term "user" defining both public servants and citizens. In the last decade digital government environments have evolved a lot, increasing the participation, transparency and integration. The use of web 2.0 technologies has made possible the move from serviceoriented architecture (SOA) to web-based architecture (WOASs). Web 2.0 technologies lead 
to a more active government interaction with the public, through various mechanisms like live chats, blogs, web comment forms for feedback from citizens, social media becoming a central component of government strategies.

Cloud computing (CC) is a distributed kit of computing services, applications, storage and data access, where the user does not have to know the location and physical configuration of the systems providing these services. For the government, $\mathrm{CC}$ is the best choice for storing, updating and protecting data, providing many benefits, main ones being flexibility, cost decrease, collaboration. Regarding the flexibility, $\mathrm{CC}$ is more advantageous than traditional technological infrastructures, eliminating the problems that arise due to limited resources, purchase and maintenance of servers and hardware equipment, data protection. Organizations that decide to use cloud services may chose various service models like SaaS, PaaS and IaaS and may implement software in public, private or hybrid cloud, depending on security requirements and budget. Storage space is no longer an impediment, in the public version being virtually unlimited, while in the private version it can be extended fast and easy.

From the cost perspective, cloud use considerably diminishes IT costs of an organization, reducing the amount paid for equipment and infrastructure. It brings the possibility to access larger computation resources without purchasing and maintaining servers, which involves extra costs for electricity, storage and qualified personnel. Additionally, there is no need to pay for various licenses and taxes for software. $\mathrm{CC}$ helps the collaboration between government agencies, allowing sharing of various documents from anywhere in the world, the only condition being a connection to internet.

$\mathrm{CC}$ paradigm provides support for the development of electronic services in an environment easy to use, with unlimited access, direct communication and real time information. The security aspect of these services must receive a special attention. There are a few main features of e-services in a digital world. One of them is scalability, indicating the ability to manage larger and larger amounts of work tasks. Cloud systems provide the best support for hosting electronic services, providing solutions for the usual problems. Thus, technologies that support and help evolve CC are needed in order to successfully apply the electronic government, one of the important manifestations of informational society involving state institutions, public and private organizations and, most important, the citizens which are transformed into e-citizens, involved into all aspects of life: political, social, economic and cultural.

\section{E-Democracy}

E-democracy, also known as electronic democracy, means the use c ICT by democratic political actors in the governing and political processes of local, national and/or international community. "Political actors" means governments, elected officials, mass-media, political organizations and, most important, the citizens. In a broader sense, electronic democracy means giving the citizens the opportunity for a more important and active participation to the governing process, through internet, mobile communications and other technologies. In this sense, most e-democracy theoreticians agree that with this concept and introducing new forms of online communication, the traditional barriers for involving the citizen int the liberaldemocratic policies can easily be overcome [1]: lack of time, community decline, lack of deliberation opportunity.

Citizen participation is necessary to build democracy, being a crucial element for controlling the leaders, a better transmission of preferences, attenuation of conflicts and reducing the costs of making political decisions. Additionally, participation promotes a type of citizen that has a better interest in being informed about the political life, cooperating with others and is more respectful towards the others, thus consolidating social links between people and favoring intercultural understanding. 
Citizens' opinions, suggestions and critics can determine the type of democracy a country can have and its quality.

At the dawn of 12st century there was an attempt to connect the online networks to the formal political processes. Central and local government agencies started to experiment with online policy discussions and consultations with citizens. Various democratic projects emerged, all centered on the use of internet. They generally followed two main directions: consultative and deliberative.

Consultative approaches highlight the communications of citizens' opinion to the government. It starts from the idea that information is an important resource that may be used to ensure a better policy and administration. The best such example is the federal USA government program for adoption of electronic rules, which allows the citizens to comment on the department and agency rules as they are being developed.

Deliberative or discursive democracy is a form of democracy where deliberation is centered on making decisions and is based on the rule of majority. This differs from traditional democracy because authentic deliberation, not only voting is the main source of legitimacy for a law. Thus, in order for a decision to be legitimate, it must be preceded by an authentic deliberation, simple aggregation of voting preferences is not enough. It may be made by decision factors both in representative democracies as well as in direct democracies. As a consequence, e-democracy must be oriented on the following priorities (figure 2):

$\checkmark$ Stimulation of citizen involvement in local government;

$\checkmark$ Empowering local citizen associations;

$\checkmark$ Support for easement of digital division;

$\checkmark$ Ensuring instruments for the citizens to enable participation in decision processes on local level, where they are directly concerned.

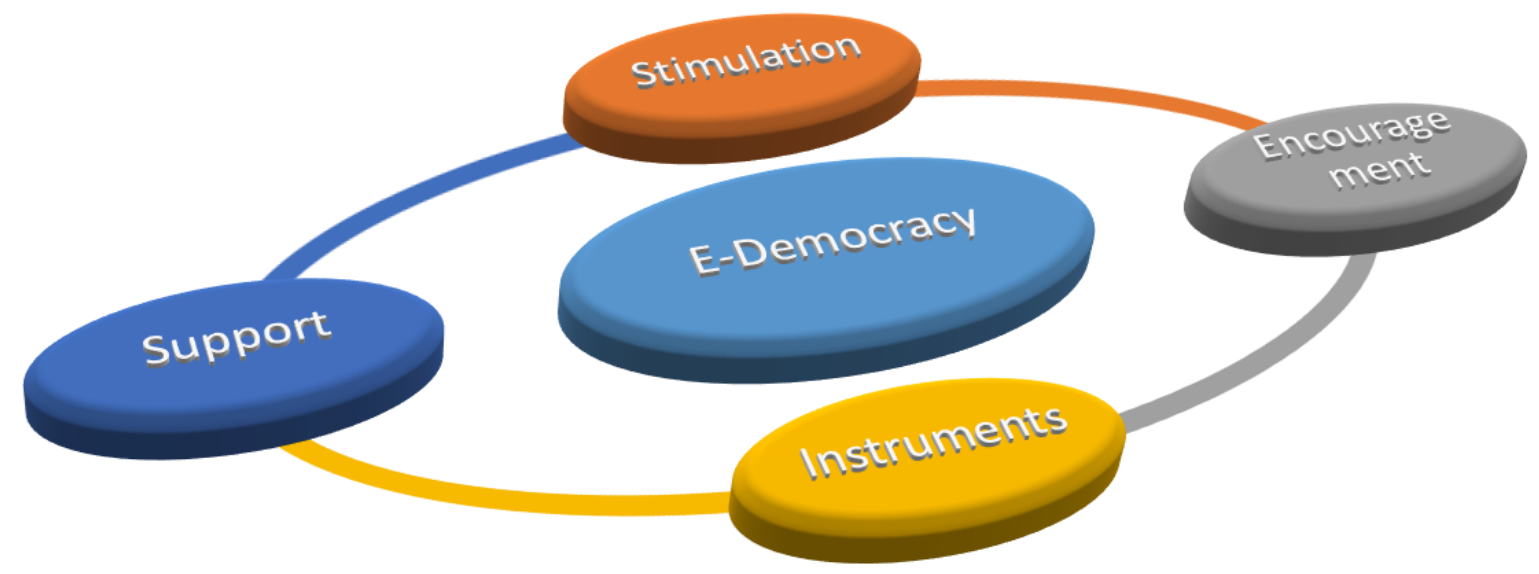

Figure 2. E-democracy priorities

Digital inclusion is essential for citizen participation on formulation of public policies, for a healthy digital democracy, through equal participation of all society sections to democracy, no matter the level of citizen income, education, gender, religion, color, ethnicity. Any public policy formulated without including any society section will forever remain non-inclusive by nature and will go against the essence of democracy.

E-democracy starts to show a significant evolution, especially due to the emergence of web 2.0 technologies. The new information processing techniques, including Big Data Analytics and Semantic Web contribute to the development of future forms of electronic democracy. Currently, the e-democracy process is supported by technologies like electronic mail lists, peerto-peer networks, collaboration software and applications (like GouvernEye, VoteSpotter, 
wikis, forums and blogs). Social sites like Facebook, WatsApp, LinkedIn, Google+, Twitter, Instagram, Pinterest, Befilo, Zoimas or Messenger play an increasingly important role in democratic deliberations. Supporters of electronic government see the government use of these networks as a mean to help leadership interact more with the public, the citizens.

\section{E-Voting}

Electronic vote uses electronic devices to help the citizens manifest their choice or help the organizers count the votes. Depending on implementation, electronic voting may use standalone electronic voting machines $(\mathrm{EVM})$ or computers connected to internet with various level of services, from transmission of results to actual online voting. The degree of automation may be limited to marking a physical paperback ballot or it may be a complete voting system, including actual voting, encoding, and transmission of the information to servers to tally the votes. The first implementation of electronic voting took place in Brazil in 1995, when electronic ballots were developed for use in 1996 municipal elections [2].

As time passed and internet penetrated the daily life, the voting process found a new form, called i-voting. This allows voters to manifest their choice from any device connected to internet, from anywhere, including from own home. Many have seen this as an opportunity to transform the democracy, allowing the citizens to directly participate to the decision-making process. Still, many countries have decided that internet is not safe enough for voting. Therefore, countries like Estonia, Switzerland, France have imposed restrictions on i-voting. Additionally, these countries consider that many personal computers are vulnerable to penetration by various types of malware which can launch attacks to block or replace legitimate votes, thus falsifying the entire voting process in an untraceable way. A third problem is the possibility of coercion against the voters and vote selling, which is easier to happen when voting takes place in an uncontrolled environment [3]. The electoral system is an essential element of democracy and transferring it into an electronic service may be pretty difficult. Electronic voting is considered an important subject for the advancement of democracy in the world. If a safe and convenient electronic system can be developed, then it can be used more often to consult the citizens, through electronic means, regarding a large variety of decisions. An efficient analysis of various types of attacks, their goals and probability may help in the process of developing an electronic voting architecture that must be secure and trustworthy. An electronic voting system, even one accessible though internet, must take advantage of the new technologies to design, build and maintain it.

Thus, the electronic voting technology in any form or shape (be it punch cards, optical scanning, voting kiosks, internet transmission of ballots, mobile phone voting etc.) is an important step for passing to electronic government, a significant advancement for a state.

\section{Conclusions}

E-democracy, digital democracy or internet democracy incorporate $21^{\text {st }}$ century technology to promote democracy. This is an integral part of digital transformation of a nation, through intelligent use of digital instruments aiming to improve and transform existing government models and practices. ICT may significantly increase the transparency, sensibility and responsibility of governments and may provide the citizens with the opportunity to participate on political processes, which will lead to better outcomes for the society as a whole. Electronic vote uses the technology to make sure the citizens manifest their choice in a fast and safe manner. Depending in implementation it can use stand-alone machines, or internet connected computers.

We can safely assert that without adapting the leading and governing methods to the technological era, a country's the dream of prosperity and the ability to provide the best services 
www.conferenceie.ase.ro

to its citizens, by involving them in the political sphere, is hard, even next to impossible, to achieve.

\section{References}

[1] M. Burnester and E. Magkos, "Towards Secure and Practical E-Elections in the New Era," in Secure Electronic Voting (Dimitris Gritzalis Ed.), Springer International Publishing Switzerland 2003, ISBN 978-1-4613-4981-5 (eBook). Available: http://link.springer.com/chapter/10.1007\%2F978-1-4615-0239-5_5

[2] M. Stoica, B. Ghilic-Micu, "E-Voting Solutions for Digital Democracy in Knowledge Society," Informatica Economică, vol. 20, no. 3/2016, pp. 55-65

[3] D.P. Moynihan, „Building Secure Elections: E-Voting, Security, and Systems Theory,” Public Administration Review, volume 64, issue 5, pp. 515-528, September 2004 